\title{
A CONTRIBUTION TO OUR KNOWLEDGE OF THE ETIOLOGY AND NATURE OF HARD CURDS IN INFANTS' STOOLS *
}

\author{
JOSEPH BRENNEMANN, M.D.
}

chicago

The curds that occur in the stools of infants, especially of those fed on cow's-milk, have been the subject of much discussion among pediatricians. A great deal of importance attaches to the solution of the problem of their etiology and nature, because their presence in the stools has always been considered an evidence of an overstepping of the infant's tolerance for the particular food element from which the curds were thought to be derived. The pendulum has swung from the first natural interpretation that they were undigested particles of curdled milk, therefore chiefly protein in origin, to the opposite extreme, if we are to accept the teaching of nearly all the foremost German pediatricians, that the casein takes no part in their formation. From observations that we have made in our clinic at Northwestern University Medical School, and from some experiments that I have made in the past year, I believe we are justifed in stating that one extreme is nearly as far from the truth as the other.

The source of confusion lies in two places: (1) There is a lack of sharp definition of different kinds of curds; (2) German clinicians, as I hope to demonstrate, use a food that differs vitally in just this tendency to the formation of curds of a certain kind, from that which we, in this country, use as a routine. For this reason, which I will elaborate, I believe that certain curds do not occur in the experience of German pediatricians as they do in ours and that, therefore, the controversy concerning them runs in parallel rather than opposing lines.

The curds of infants' stools are distinctly of at least two kinds that differ essentially in morphology, etiology and composition:

1. The small, soft, friable, yellowish or whitish or greenish curdthe common curd of milk indigestion. This requires no further description. It has been removed from the field of discussion, almost universal consent in the last few years having given it predominatingly a fat origin. This curd occurs both when breast-milk and cow's-milk are fed.

2. The large, hard, tough curd. This curd bears no morphologic resemblance to the former, nor does it occur under similar conditions.

*Read before the Chicago Pediatric Society, Feb. 21, 1911. 
It varies in size from a mere shred or that of the head of a pin to that of a lima bean or even that of the distal phalanx of a thumb. It is commonly the size of an ordinary white bean and is generally beanshaped, or oblong or rounded, though often, especially if very large. it is quite irregular. It is always hard and usually can be broken or crushed only with considerable force. It is of about the consistency and appearance of hard American cheese. It can be picked out of a stool with a pin or a stick, without being injured, as definitely as can a bean. So strongly is its resemblance to a soaked bean stripped of its coat that at Northwestern we commonly call them "beans," for short. On one occasion a Mr. McGuire reported at the diet kitchen that "Elizabeth wasn't doing well at all, but what could you expect when the woman was feeding it beans," and he exhibited a very convincing diaper. These curds can be washed in water with great force, shaken in water in a bottle, for example, without any tendency to disintegration, and always sink rapidly to the bottom. When separated and dried they form dry, hard, shriveled, semitranslucent masses that resemble pieces of gelatin, or of horn. Finally they crumble to a coarse crystalline powder when touched, or even crumble spontaneously.

These hard curds are either white or dough-colored, or even light greenish; or else a pale, brownish-yellow or amber color. The former are softer and more nearly friable, usually more rounded than the latter and are accompanied by a greater degree of indigestion, as shown by the occurrence of mucus and an increased number of bowel movements. The yellowish or amber-colored curds are always very hard, and can be bent without breaking. They are often accompanied by indigestion, but about as frequently occur in an otherwise nearly normal movement. The two varieties of hard curds rarely, if ever, occur together, but one kind may merge into or follow the other with the baby on an identical food, depending on whether the indigestion improves or gets worse. For this reason, and because of their striking points of resemblance, there can be no doubt that they have a common origin.

The present discussion deals wholly with these hard curds. They are distinctly rarer than the soft curds when certain kinds of food mixtures are used, distinctly more frequent when others are used, and, again, never occur when certain conditions are complied with. They do not occur in breast feeding.

The present state of our knowledge of these hard curds has recently been focused in a rather heated discussion between Fritz Talbot of Boston on the one hand, and Ludwig Meyer of Berlin, and Jerome Leopold of New York, on the other. Talbot has published a series of articles on the subject of hard curds and presents an array of evidence that has convinced him that they are of casein origin, in contradistinction to the 
small, soft curds that he, too, has found to be derived chiefly from the fat. Meyer and Leopold categorically and "with considerable warmth deny all of Talbot's assertions. They speak constantly of "casein masses," not, however, in the sense in which Talbot uses the term, i. e., to designate hard curds, but as a general term synonymous with curds. When Talbot in a later paper takes them to task for not clearly differentiating between small, soft and large, hard curds they emphatically refute this criticism. A careful reading of their papers in the light of my own experience convinces me, nevertheless, that Meyer and Leopold are not using the term "casein masses" as synonymous with hard curd, even when especially asserting that they do. The only possible explanation for such antagonistic opinions about so decided a phenomenon can be found in the fact that Meyer and Leopold are not practically familiar with the hard curd that Talbot, Southworth, and other American observers have described so unmistakably.

The matter assumes greater importance when we realize that in this respect Meyer and Leopold represent all of the leading German authorities, Heubner, Czerny, Finkelstein, etc.

The explanation for this lack of familiarity lies, of course, not in a lack of observation; no one would ever accuse a German pediatrician of all others, of that; but in the simple fact that these curds do not occur in their experiences, while they are common in ours, for reasons that I will elaborate presently.

The arguments that Talbot presents are, to my mind, alone convincing that these hard curds are derived from casein. The evidence that I will present will, I believe, help to clear the matter because it will enable Meyer and Leopold to make these curds experimentally, so that they too can see and study them.

That the hard curd is of casein origin seems probable from its very appearance and consistency. It is, a priori, almost unthinkable that it is a fat, or a salt, or a bacterial, or an intestinal secretion derivative.

Further, when fat-free milk is coagulated with rennin and then broken up, the large curds, if separated, continue to contract and express whey. They then shrivel up into hard semi-translucent, horn-like masses and finally crumble in the fingers to a coarse powder, all of which bears a striking resemblance to what takes place in these hard curds when allowed to dry in the same manner. The curd of whole milk does this less readily and remains less dry, as if dipped in butter.

Furthermore, as Talbot has shown, and as I have been able to confirm, when a mass of curdled milk is left four to six hours in 10 per cent. formaldehyde solution it becomes as hard as a billiard ball; in fact, Talbot tells us that this principle is employed in the manufacture of 
billiard balls. An identical result is obtained when a hard curd is thus treated.

Microscopically, too, Talbot has shown that there is an identical appearance in hard curds and in curds made artificially by coagulating milk with rennet, and digesting the resulting curds for one hour at $98.6 \mathrm{~F}$. with pepsin and 0.2 per cent. hydrochloric acid, and then, after washing, further digesting them for one and one-half hours with a fresh 25 per cent. alcoholic extract of pig's pancreas in 5 per cent. of carbonate of soda. In both natural and artificial curds there is found a white, shining, translucent network in which numbers of neutral fat drops are entangled, that evidently could not be reached by the digestive juices because of their casein envelopes. Small curds, on the other hand, as one would expect, show the fat almost entirely in the form of fatty acids and soaps.

Talbot furthermore was able to demonstrate that "curds made and digested artificially give exactly the same physical and chemical composition as natural curds." He was "able to dissolve and precipitate these tough curds, in the same way as casein, by weak alkaline and acid solutions. This precipitate was obtained in as pure a state as possible and found to contain nearly the same percentage of nitrogen as Hammerstein's pure casein."

In spite of this evidence Meyer and Leopold maintain that casein takes no part in the formation of these curds; that the nitrogen is derived from some other source, possibly, as Langstein suggests, from the intestinal secretions. Talbot then brought out a proof that these hard curds do contain casein by showing that they give a specific biologic reaction. He prepared a specific anti-cow casein serum by injecting rabbits with cow casein. With lactalbumin and human casein he obtained no precipitate with this serum, but with cow casein and with the hard curd the reaction was positive. Normal stools not containing these hard curds gave no such reaction.

That these curds are not derived from the fat of the food is demonstrated by the fact that they occur just as frequently with the use of fat-free milk as with whole milk, or cream; in fact, in my experience, for reasons that will appear later, they have occurred predominatingly. with fat-free milk. In all of the experiments that I will present certified, centrifuged, fat-free milk was used.

When Czerny's chapter on Milchnaehrschaden first appeared we were convinced, in the light of former experiences, of the truth of its teachings concerning curds and protein digestion and increasing experience more and more confirmed the view that there was no pathologic clinical picture which could be recognized as due to casein. Prior to this time we had been followers at the clinic of the so-called percentage method of feeding. 
We fed high fats and low proteins and commonly "split" the latter to get away from the "casein" curds that constantly followed us. Babies were fed almost exclusively on cream and milk and whey mixtures and while we saw innumerable small fat curds the hard curd was so rare that I, perconally, had never thought of it as a distinct clinical entity. Convinced that the protein was harmless we fed it boldly in fat-free milk in almost any amount and in almost any condition and were more and more impressed with its harmlessness. The curds that we had seen so frequently formerly never appeared so long as we used fat-free milk alone.

Only one thing stood in the way of our happiness and that was the appearance in certain cases, for the first time in our experience, of an apprcciable number of hard, bean-like bodies in otherwise fairly normal. fat-free milk bowel movements. After a time we noticed that these hard curds came fairly regularly when we exceeded a certain amount of fatfree milk. Personally, I came to expect them in the less tolerant cases whenever I exceeded 2 ounces of fat-free milk to the pound of baby and I gradually thought of this as almost the limit of tolerance for many. ases. When the limit of tolerance was exceded there often appeared other eridences of indigestion, the bowel movements became paler and softer, rontained mucus and became noticeably more frequent. $\mathrm{Up}$ to this time we used raw milk practically exclusively. To counteract the diarrhea, we resorted to the time-honored expedient of boiling the milk, and found almost without exception that the digestion improved, and that without any exception the hard curds disappcared in a day or two without otherwise altering the food. Since that time we lave nearly always boiled the milk in these less tolerant cases, always to begin with, and now again we never see the hard curd in our own experience at the clinic except as a result of a mistake in judgment. In all of our experience we have never seen a hard curd unless a considerable amount of raw milh casein uas given and we have never seen them persist or occur when boiled milli, no matter in what amount, uas given.

In a case of decomposition (Finkelstein) in which $I$ had been feeding the patient boiled fat-free milk for some time, hard curds suddenly appeared in the stools for the first time. I expressed my regret to the mother that she had not carried out my order to boil the milk. She maintained that she had boiled it and I stated positively that the baby had had raw milk. She then suddenly remembered that in her long-extended anxiety and slecplessness she had become absent-minded and had wholly forgotten to boil the milk on the previous day. The curds never again appeared.

To do away utterly with the possible element of coincidence I decided to make and unmake hard curds at will, in babies, by the simple expedient of using raw and boiled milk alternately. The result was as precise as 
a chemical reaction in a test-tube, in each of four babies, i. e., in every baby in which it was tried.

These four babies represented different pathologic conditions and different ages. Sone of them was, of course, reritically ill at the time of the tests themselves. They were watehed with the utmost are and none of them became ill during the tests except for a slight temporary diarthea in some of the eases. Inasmale as the fat was climinaterl and the sugar low in the foocls, I felt that there was no possible danger to the bahies from the serious disturlances, such as an intoxication. 'The remedy was always immediately at hand it a baby became only slightly ill, and inasmuch as the remely consister in boiling the milk the course of the experiment was not disturbed.

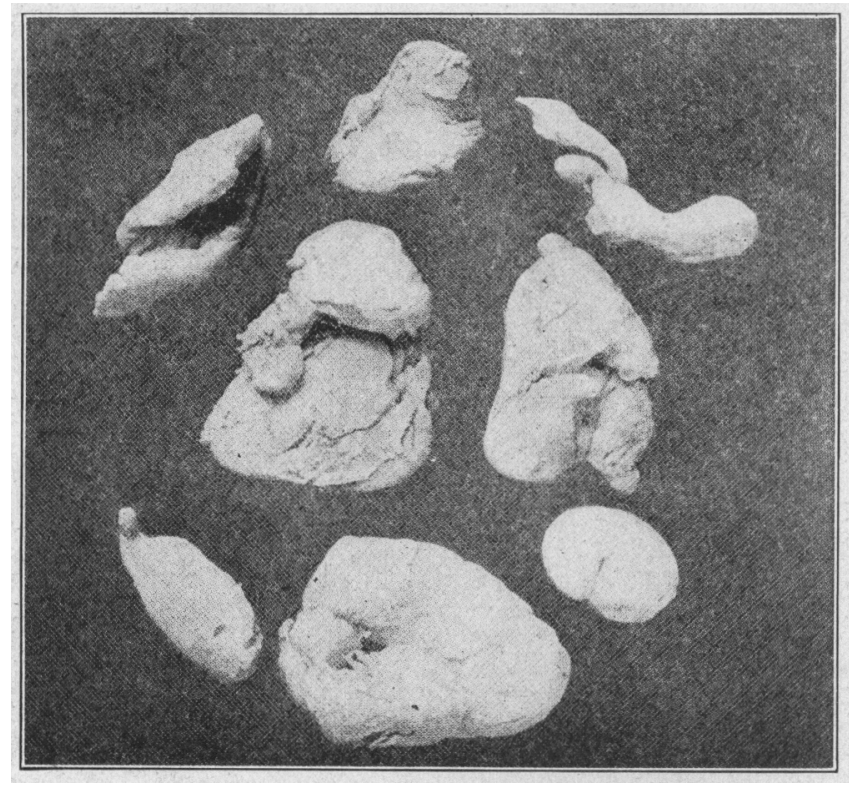

Fig. 1.-Casein curds, actual size (taken from Talbot). The curd in the lower right hand corner shows the ustal size and appearance of the commonest bean-shaped hard eurd. The larger ones show the indentations that appear, as though portions of the curds had been digested ont. These curds are so evidently identieal with those deseribsed in the text, especially to those who have seen them often, that no apology is necessary for utilizing this excellent photograph.

In every ase certified, centrifuged fat-liee milk was the only milk uscd. The reason for this was fourfold: (1) It was the fool that seemed indicated therapeutically; (2) it eliminated largely the fat in fetermining the origin of the hard rurds; (3) hard curds are mate more easily with fat-free than with whole milk; $(4)$ and most important, it eliminated practically all source of danger to the baby. Whole milk in a 


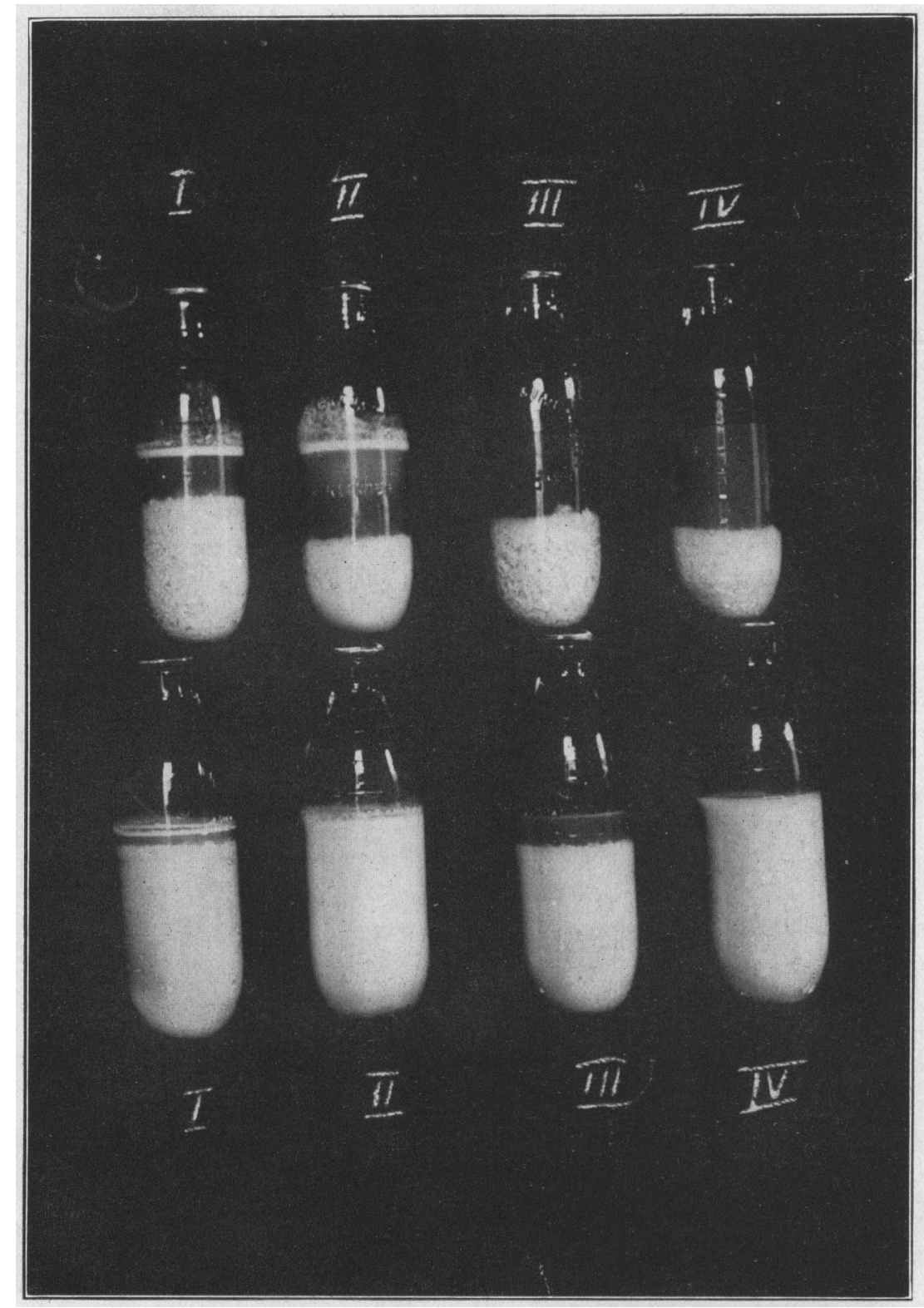

Fir. 2.-Photograph showing the effect on milk eongulation with rennin of boiling and of dilution with water. Fach of the abose bottles of milk was treated

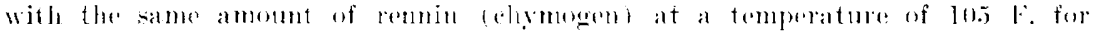
thirty minutes, then shaken. cooled. and allowed to stand for forty homrs. The

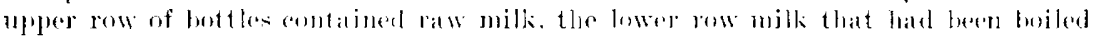
five minutes. Bottlen I rombined moljluted whole milk: bottles II. enual parts

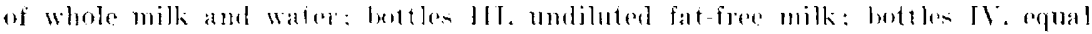
parts of fatefree milk and water. Sote the ereater separation of whey in all the

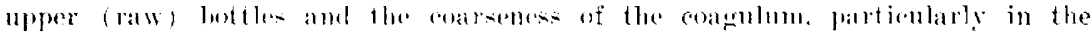

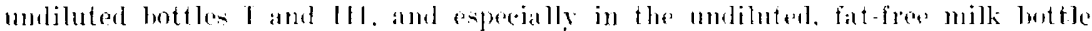
illf). In the lower row is shown the very inperfere separation of wher, and the fineness of the eoagulum when the wilk is loilod and espedially when also dihuted, as in lottles $1 \mathrm{~J}$ and IV. 


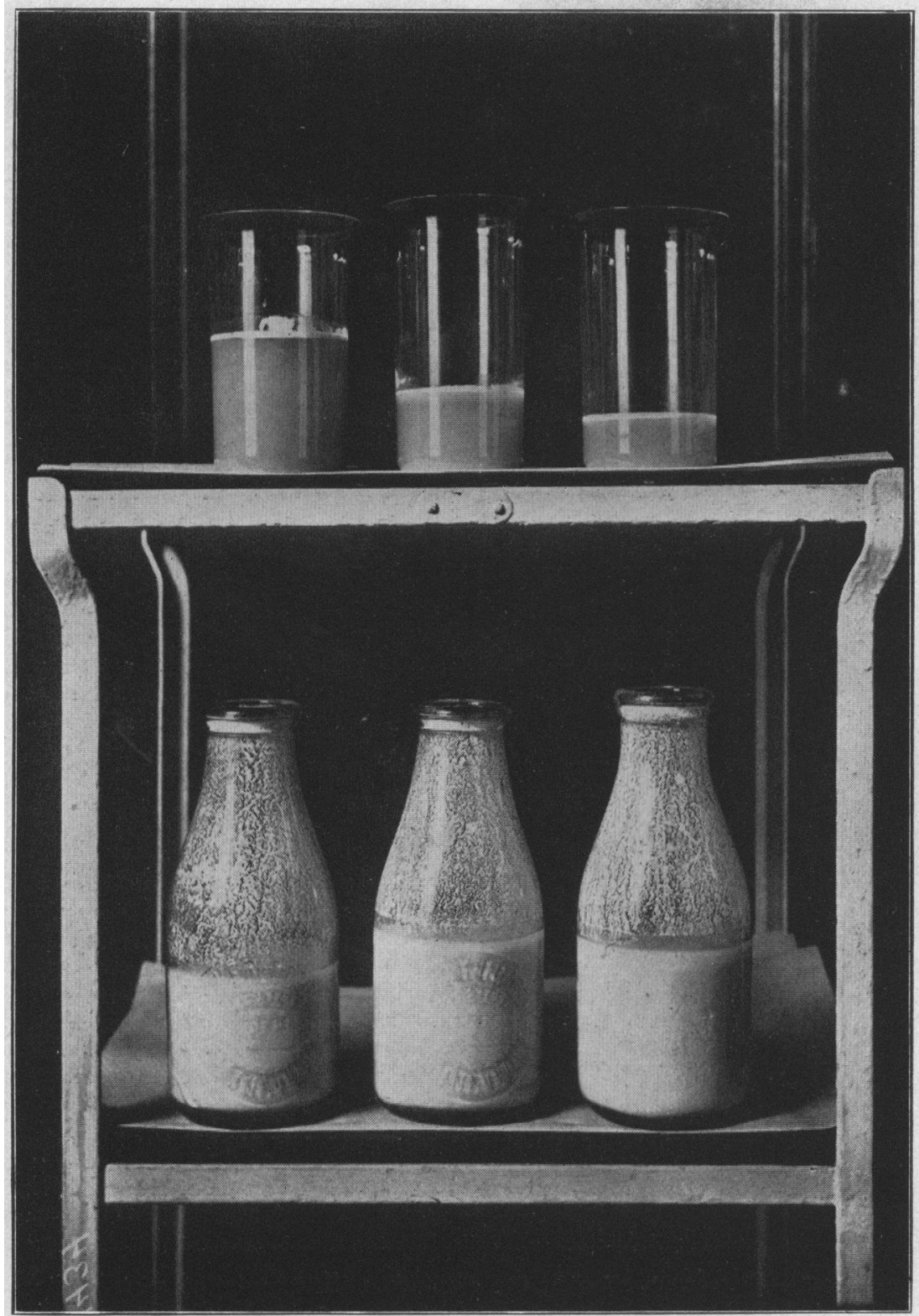

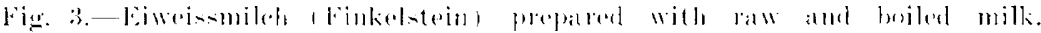

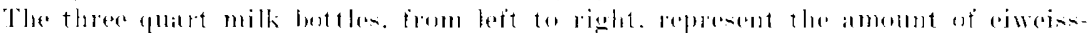

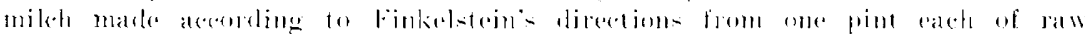

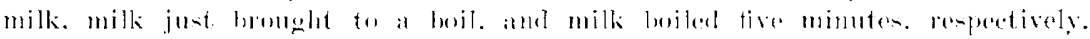

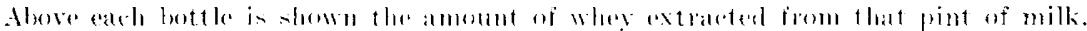
With baw milk the Whey was about domble, and the dord alout one-half (by

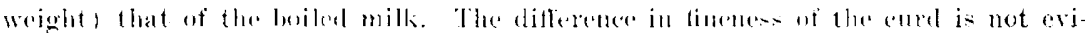
dent, in the photogritpl. 
sufficient amount to give an abundance of hard curds would probably have produced many small fat-curds, or a soap stool, or would have been a serious menace to an atrophic infant. The fact that none of the babies suffered in any way beyond a slight temporary indigestion demonstrates again the insignificance of the rôle played by the proteins in nutritional disturbances as compared with the fat or the sugar. When the milk was boiled this was done in a single boiler for two to five minutes. In every instance the food was begun at $4 \mathrm{p}$. m., the stools inspected the next forenoon, and a day corresponded to a calendar day.

It will be necessary to give these cases in sufficient detail to show the conclusiveness of the evidence.

\section{CASE REPORTS}

CASE 1.-Baby B., aged 4 months, weight 10 pounds 5 ounces; nursed two months, then fed cow's-milk whenever it cried, had been sick ever since; had five to six dyspeptic stools a day. The baby had a typical, profound intoxication (Finkelstein), with low fever.

The patient entered Wesley Hospital Oct. 7, 1910, and was put on boiled fatfree cow's-milk, 15 ounces, barley water, 15 ounces, for three days. In the next two weeks the food was gradually increased to fat-free cow's-milk (boiled), 22 ounces, and human milk, 10 ounces a day. In the first week there were five to nine dyspeptic stools a day and the child was generally edematous, with dry, hard, leathery skin and tissues. During the second week these symptoms all disappeared, the look of intoxication was no longer present, the digestion became normal, the baby had one or two stools a day and gained 2 ounces. Up to this time the cow's-milk was always boiled and no curds had appeared.

October 20. The milk was now ordered raw and consisted of fat-free cow'smilk, 22 ounces, human milk, 5 ounces, barley water, 13 ounces, flour-ball, 3/4 ounce.

October 21. One normal stool, no curds.

October 22. Two stools, one at 1 a. m. contained one hard curd and a later stool had three large, white hard curds the size of small lima beans. The first curd appeared thirty-three hours after food was given raw.

October 23. Four stools containing hard curds.

October 24. Seven stools each containing large, hard, whitish curds varying in size from a small pea to a large marble, or filbert, and forming often apparently more than one-half of the bulk of the movement. The rest of the stool was liquid and greenish.

Because curds often appear more freely when undiluted milk is given, to eliminate further the additional carbohydrate, and for more accurate experimental purposes, the baby was now put on 30 ounces of raw undiluted fat free milk.

October 25. Five stools of same consistency, each containing large, white, hard curds. The same food was now given boiled five minutes.

October 26. Five loose, somewhat greenish stools; 2 a. $\mathrm{m}$. stool had a few yellow or amber-colored curds the size of a split pea. Baby looked better.

October 27. Four stools. Two contained hard curds, one a few small yellow ones; the other has several larger and a number of smaller yellow curds. No more curds after the 12:30 stool, i. e., forty-four hours after the milk was boiled.

The baby was kept on this same fat-free milk, 30 ounces, for six days. It had four or five thin but greatly improved stools a day, in none of which were there any curds. Baby in good condition.

November 2. Same food, 30 ounces fat free milk again ordered raw. 
November 3. Four stools; fourteen hours after beginning raw milk one stool contained many typical, large, whitish curds the size of a lima bean.

November 4. Four stools. One contained one very large, hard curd; the rest all had several small, yellow, hard curds.

November 5, 6 and 7 . During these three days the baby had four and five stools a day, some of which each day contained small and large yellow hard curds. The food was then changed to whole cow's milk, 12 ounces, barley water, 18 ounces, boiled five minutes.

November 8. Four stools. Two large yellow curds in the morning stool, none after that. During the next four days $1 / 2$ ounce of a malt food was gradually added to the food. The stools became normal, rather constipated, with no curds of any kind at any time. The baby left the hospital five days later in excellent condition, having lost only 11 ounces in spite of the severe intoxication and edema at the start.

In this baby we felt in advance, on account of its age and recent dyspepsia, that we had a favorable case for large curd formation. The large, white curds of the first trial were an evidence of a severer reaction; the smaller, yellow, harder curds of the second trial showed that the child's ability to handle an excessive amount of raw fat-free milk had improved greatly. Especial interest attaches to the fact that in spite of the sudden addition of a considerable amount of fat in the 12 ounces of whole milk, and of carbohydrate in the form of barley water and malt food, no more curds appeared when the milk was boiled five minutes.

Case 2.-Baby W., entered Wesley Hospital Nov. 20, 1910. Age 51/2 months, weight $71 / 2$ pounds; had lost 6 pounds; breast-fed one and one-half months; then a fine fat baby. The infant was then put on various foods, finally on pasteurized cow's-milk. It was always extremely constipated, so that it had marked prolapse of the rectum.

Diagnosis, simple malnutrition. On account of the good digestion and marked constipation the baby seemed especially favorable, because it would not be likely to be acutely upset.

From Nov. 30, 1910, to Jan. 20, 1911, the infant was given various whole-milk, fat-free-milk and human-milk mixtures with carbohydrate additions. The cow'smilk was always boiled. The child was so constipated that commonly $1 / 2$ ounce of milk of magnesia was added to the food. For one month the baby was now kept on the same food, 30 ounces of fat-free milk, daily.

January 20. Put on fat-free milk, 30 ounces, boiled five minutes.

January 21. Two stools. No curds.

January 22. One stool, constipated, no curds.

January 23. Two normal fat-free milk stools. No curds. Milk ordered raw. January 24. One stool, dry and constipated. No curds.

January 25. One lighter, softer, stool containing many small yellowish beanlike curds, about thirty-two hours after raw milk was started.

January 26. Two stools. Each had large and small, hard, yellow curds, larger than on the previous day.

January 27. Two stools. First had six or seven small, yellow curds; second had more hard yellow curds than any previous stool.

January 28. No stool. Milk boiled two minutes.

January 29. Two stools. Three hard yellow curds. None after twenty-four hours of boiled milk.

January 30. One stool. Very constipated. Stool like marbles. No curds.

January 31. Two stools. No curds. Same food again ordered raw.

February 1. One stool. Seven large and small yellow curds within fourteen hours of giving raw milk.

February 2. One stool softer and paler; seven yellow curds of medium size.

February 3. One stool; seven yellow curds. 
February 4. One stool; eleven yellow curds, some quite large. Sodium citrate, gx. $\mathrm{xxx}$, added to the same raw milk.

February 5. One stool; same number and size of curds.

February 6. One stool; same color and consistency. One large and two small yellow curds.

February 7. One stool, same as before, contained six yellow curds. Sodium citrate, gr. lx, added to same milk raw.

February 8. Two stools. First, at 10 a. m., had seven or eight very small, yellow curds; second, in the afternoon, contained no curds. Sodium citrate reduced to 30 grains.

February 9. One stool; one large and several smaller hard yellow curds. Sodium citrate again increased to 60 grains.

February 10. One stool; six very small, yellow curds.

February 11. One stool; no curds. Curds ceased as before in twenty-four hours when sodium citrate was increased from 30 to 60 grains. Sodium citrate omitted. Milk still given raw.

February 12. One stool; first part hard and contained no curds.

Last part of same stool was softer and contained two yellow curds.

February 13. Two stools; each contained several hard, yellow curds, one very large.

February 14. One stool; contained a number of very large, hard, yellow eurds and several smaller ones. Milk ordered boiled two minutes.

February 15. One stool; two large and three small yellow curds.

February 16. One stool. No curds. Same milk ordered raw.

February 17. Two stools. One early a. m. had no curds. One at $7 \mathrm{p} . \mathrm{m}$. contained twenty to thirty large and small hard, yellow curds.

February 18. One stool liquid, pale yellow. About twenty medium and small, paler yellow, nearly whitish, softer, hard curds. Milk at once given boiled two minutes, because of the condition of the movements.

February 19. Two stools. One at 2 p. m. had several small, harder, yellow curds. Second at 9 p. m. contained one very small curd the size of two pinheads and several shreds.

February 20. No stool.

February 21. Two stools, no curds; baby in good condition.

A special point of interest in this case is the fact that when enough sodium citrate was given its action in stopping the formation of curds was identical with that of boiling the milk.

CASE 3.-Baby S, aged 23 months; weight 14 pounds; undersized child with typical Milchnaehrschaden (Czerny); typical soap stools. In this case I had considerable misgiving as to our ability to produce hard curds at all, on account of the child's age and good digestion and I felt that large amounts of undiluted fat-free milk would have to be given to reach the desired result.

October 17. The child entered Wesley Hospital and was given water until the following morning.

October 18. The following food was ordered: Fat-free milk, boiled, 18 ounces, barley water, 18 ounces, flour-ball, $1 / 2$ ounce.

October 19 and 20. Child normal in every way. Food increased to fat-free milk ( $r a w$ ), 28 ounces, barley water, 8 ounces, flour-ball, $1 / 2$ ounce.

October 21 and 22. Bowels rather constipated; no curds; food increased to fat-free milk (raw), 32 ounces, barley water, 10 ounces, flour-ball, $1 / 2$ ounce.

October 23 and 24. No change of any kind. Food now limited to fat-free milk 48 ounces raw.

October 27. Sixty hours later one or two stools contained yellow, hard curds.

October 28. Three stools with several large bean-like, yellow curds in one of them.

The child was now put on whole milk, raw, 10 ounces, fat-free milk, raw, 23 ounces, barley water, 15 ounces, flour-ball, 1 ounce, thus adding fat, increasing 
the carbohydrates and lowering the protein and salts only. For the next eight days the child had daily from one to two movements that were well digested and contained no curds. The food during this time was gradually increased to whole milk (raw), 20 ounces, fat-free milk ( $r a w), 13$ ounces, barley water 15 ounces, flour-ball, $1 \frac{1}{2}$ ounces. This, together with some additional soft food, brought on a slight diarrhea, with three to five stools daily on November 6,7 and 8 , and on the 9 th there again appeared several yellow, hard curds. The same food was now boiled; the digestion quickly became normal in every way and no more curds were found. The child gained 2 pounds during the four weeks in the hospital. At no time were the curds abundant, but they were morphologically identical with those of the previous baby and were always, as one might expect, of the hard, yellow type that accompanies less severe disturbances.

CASE 4.-Baby K., 6 months old, weight 11 pounds; very pale; simple malnutrition; no stool for first forty-eight hours in the hospital. The infant entered Wesley Hospital Oct. 16, 1910, and was given fat-free milk boiled 5 minutes, 15 ounces, barley water, 15 ounces, flour-ball, $1 / 2$ ounce.

October 17, 18 and 19. One movement daily, normal in every way.

October 19. Same food ordered given raw.

October 20. Stools normal with enema. Fat-free milk raw increased to 22 ounces; food otherwise the same.

October 21. One normal stool.

October 22. Four stools. Nearly all of them contained a number of yellow, hard curds. Food increased to fat-free milk (raw), 24 ounces, barley water, 12 ounces, flour-ball, $1 / 2$ ounce.

October 23. Three stools, containing some curds as before.

October 24. Four stools, no curds.

October 25. Five stools. Only one of these contained small yellow curds.

October 26. Three stools, with a few small yellow curds. As in the previous cases the food was now changed to undiluted raw fat-free milk-in this case 36 ounces.

October 27. Six stools. Last one contained several yellow curds.

October 28. Five stools. One contained several small bean-like yellow curds.

October 29. Three stools. First one contained several large yellow curds.

October 30 and November $I$ and 2. Five, two and five stools, respectively. No curds.

November 2. Five stools. A few yellow curds in one of them. Milk now ordered boiled.

November 3. Five stools. One curd in one of them.

November 4. Five stools. No curds except a few the size of a pin head in one of them. No more curds after that, even when put on whole milk (boiled), 12 ounces, barley water, 18 ounces.

The infant left the hospital November 21 , in good condition. In this case the baby was older and heavier than baby $B$, had no digestive disturbance to begin with, and its ability to handle a large amount of raw, fat-free milk was much greater, as shown by the fact that the curds were never abundant, were always of the hard, yellow type, and even showed a tendency to disappear while on raw milk. A larger amount of raw milk would doubtless have caused more curds to appear, but the frequency of the stools did not warrant such a procedure.

Having now demonstrated that in all of the cases in which it has been tried (and one would hardly be justified in trying it on more cases, even though the experiment is harmless), hard curds have been made to appear when a sufficient amount of fat-free milk was given raw, and made to disappear, without an exception, when the milk was boiled, I believe one is justified in making a general application of this fact, especially so when 
combined with our former extensive collective experience at Northwestern, in which the same condition was always found.

That whole milk will produce the same hard curds will be doubted only by one who has never seen identical hard curds when whole milk was fed raw. That they occur only infrequently when whole milk or cream mixtures are used is easily explained by the fact that nearly always the fat or the added carbohydrate will produce serious disturbances long before so small an amount of casein, if we may accept this as the origin of hard curds, will produce any changes. Then too, on account of its greater food value, whole milk is used in less amount than fat-free milk would be for the same baby. For reasons which will appear later, it is very probable that hard curds are formed more readily with fat-free milk than with whole milk or cream. For curds to appear in fairly normal babies the raw milk must be excessive; the more nearly undiluted the more likely are curds to appear; or the baby must be in a condition that cannot yet be defined sharply in which it cannot handle even a small amount of raw milk. Thus in the two more delicate cases, Baby B. and Baby K., curds began to appear when 2 ounces af raw, fat-free milk to the pound of baby were given. In Baby W., which seemed to have a better digestive capacity in every way, curds appeared with 3 ounces, and in the older child, Baby S., with a practically normal digestion, even $31 / 2$ were required.

An explanation of the phenomena I have described does not seem hard to find. In the last year I have made a large number of experiments to determine the difference, in vitro, of raw and boiled milk in the presence of rennin. This difference, in a general way, is familiar to all of us, and yet we have not been sufficiently impressed with it, nor have we made such practical applications as readily suggest themselves. I will give in a general way only those features of these experiments that have bearing on the main point here at issue.

Undiluted raw milk when treated with rennin at body temperature will thicken in a few minutes, will then form a firm, hard jelly that will hardly fall from the inverted beaker. This clot then contracts to a smaller bulk while whey is separated from it. If broken up with a spoon at the end of fifteen to thirty minutes there will be a definite separation of large cheesy curds, and a more or less clear whey. If the curds are separated from the whey and set aside it will be found that they naturally keep on contracting with the further expression of whey. They soon become as hard as the white of a hard-boiled egg. If allowed to dry longer they finally resemble pieces of hard gelatin or horn, very strikingly like the hard curd dried in a similar manner.

If, now, undiluted cow's milk that has been boiled for five minutes is treated in the same manner, very significant differences are soon appar- 
ent. Coagulation is not only greatly delayed, but even at the end of half an hour at a temperature of 100 to $105 \mathrm{~F}$. the curd is very soft and friable, about like a good custard. When this is now broken up as before with a spoon there is no marked separation of hard curd and whey, but the whole mixture still looks like a thick, fluid milk, about the consistency of buttermilk. On drinking it one notices only a slight thickening of the milk; distinct curds are not evident.

If the experiment is repeated with diluted raw milk, say equal parts of raw milk and water, a further striking change is noted. Coagulation is much retarded and the resulting curd is less firm and tough. Nevertheless, when the coagulum is beaten up the mixture will consist, as before, of firm separated curds, less tough, however, than when undiluted milk is used, and whey. If an identical dilution of milk and water is boiled for five minutes and then treated with rennin, there is almost no perceptible coagulation and only the slightest thickening, even at the end of thirty minutes.

With other dilutions, and with different lengths of time of boiling, the following general principle is established: The more milk is boiled, or the more it is diluted, the slower the coagulation and the less firm the coagulum. Or, in other words, the rapidity of formation and the firmness of the coagulum vary directly with the amount of casein, and inversely with the length of time of boiling. Milk diluted more than onehalf and boiled ten or fifteen minutes is practically non-coagulable with rennin in such amounts as was used in these experiments. Pasteurized milk acts in this respect like raw milk.

When fat-free milk is used in these experiments instead of whole milk the resulting curd is tougher (almost leathery when the milk is raw and undiluted) than with whole milk. When dried this same thing is equally true; the resulting curd from raw, undiluted, fat-free milk is nearly white and becomes hard as bone, long before the yellower, softer, more friable, greasy, whole milk curd has become nearly so hard. The latter is doubtless due to the fat held in the casein. Ultimately when continued drying takes place these curds will crumble between the fingers into a coarse crystalline powder just as do the hard curds from the stools. In both natural and artificially made hard curds Talbot found further that the fat content varied directly with the amount of the fat in the food and in the milk from which the artificial curds are made, respectively.

In vitro, then, if we thought of the contents as food, raw milk and especially raw fat-free milk would be considered a mixture of a solid and a liquid food, and boiled milk would be a liquid food, very similar in this respect to an infant's natural food. 
But we are told by Czerny that deductions made from what goes on in the beaker cannot be applied to conditions in the stomach. He states, furthermore, that if the milk is constantly stirred or agitated in a beaker firm coagulation cannot take place.

Simply to confirm this finding I did the following experiment and was astonished at the result. In four beakers containing 4 ounces each of undiluted, whole, raw milk, undiluted whole milk boiled five minutes, undiluted fat-free milk raw, and undiluted fat-free milk boiled five minutes, I placed the same amount of chymogen (about 71/2 grains) and kept them at a temperature of 100 to $105 \mathrm{~F}$. for fifteen minutes. Duplicates of each of these were made and while the one set was allowed to coagulate undisturbed, the other set was constantly and vigorously stirred with a spoon. At the end of fifteen minutes the contents of each of the eight beakers was stirred vigorously.

In the case of the undiluted, raw, fat-free milk that was stirred constantly the separation of curd and whey was most complete and the curds were large, from a pea to a marble in size, and were more tough and leathery or rubbery than I had ever seen them before, while in the undiluted, fat-free milk not stirred the separation was less complete, and the curds smaller and much more easily divisible. In the raw whole milk the difference was even more striking, possibly due to the fact that some one else stirred this beaker and may have used more of a rotary than a criss-cross motion. In the unstirred beaker the separation was fairly complete, but the whey was milkier, while the curd was quite firm but still easily divided into smaller curds on stirring. In the beaker that was stirred constantly the whey was very milky and practically all of the curd was in one tough ball nearly the size of a walnut.

In the boiled, undiluted, whole milk beaker that was unstirred, the mixture after stirring at the end of fifteen minutes was simply a thickened milk in which one could not recognize separate curds on testing it. In that which was stirred the milk showed a distinct tendency to separation into a paler solution containing small easily visible and tastable, rather firm curds, about the size of a pin-head. In the boiled, fat-free milk beakers there was the same condition, only the curds were tougher, and the milk was decidedly gritty to the taste in the stirred beaker.

Each of the eight beakers of milk treated as an unknown could at once be recognized and especially could the stirred mitk in each case be distinguished from the unstirred milk on account of the greater distinctness, size and firmness of the curd.

One can only agree with Czerny that the conditions in vitro and in the stomach are probably different, but it would be as easy from this experiment to conclude that motion favors hard curdling, as to deduce from his experiments that curdling is inhibited. Fortunately we do not 
need laboratory experiments to convince us that milk can curdle in the stomach in large, hard clots. Those of us who have fed raw milk have repeatedly seen infants with disturbed gastric digestion, if I may use the term, vomit firm, leathery curds larger than the end phalanx of a large thumb. Czerny probably has not seen these large stomach curds because he uses boiled milk exclusively.

It seems to me, then, quite plausible that tough curds are formed in the stomach of an infant when fed raw milk; experimentally, in a healthy infant when the casein is excessive and especially when undiluted, and clinically in a dyspeptic infant when its tolerance for raw casein is overstepped, no matter how small an amount is given; and that these hard curds are resistant to digestive liquefaction and pass through the intestinal tract without complete disintegration. This is evidenced by the fact that the curds, when there is considerable diarrhea, are passed through rapidly and are abundant and whiter and softer, and when the baby is constipated they are more yellow and always harder, as if they had had a longer time to express whey content and also a more prolonged exposure to the digestive juice, leading to a reduction in size. These harder curds often look as if they had had holes digested into them while the softer ones are nearly always more rounded and even.

Tobler has stated that "it is highly improbable that such a casein mass should pass through the whole intestinal tract undigested." It is hard to see why such tough curds as we have seen in the test-tube and as we have seen romited from an infant's stomach, should not pass through as undigested as other pieces of all kinds of solid food, that we are familiar with in infant and adult. It is quite inconceivable, it is true, that any casein curd from boiled milk could pass through undigested.

That such large bodies can easily pass the pylorus is shown in the cases where pennies, safety-pins, marbles and what not are passed.

That the presence of hard curds in the stools is due to the formation of large curds in the stomach seems further highly probable when we know that they will disappear as well when enough sodium citrate is added to the milk as when it is boiled (see case of Baby W.). Milk treated with sodium citrate acts in the test-tube like boiled milk as far as coagulation is concerned, and it is reasonable to assume that it is the lack of firm coagulation in the stomach that causes the curds to disappear in both cases.

German pediatricians use boiled milk in feeding their babies. We, in America, use raw milk almost as much, as a routine, as they do boiled milk. How deeply the hobgoblin of scorbutus has influenced us is shown even in the attitude of the mothers, who immediately wonder if they have called the right physician to see the baby if he asks to have its milk boiled, even if only for a few days. It seems to me then, that, for the above 
reasons, we are justified in concluding that these hard curds do not occur in Germany while they are not uncommon with us. If they did occur there they long ago would have been accurately described (and the descriptions of "casein masses" by German clinicians are certainly indefinite now as compared with Talbot's and mine), they would have been analyzed, their origin determined and the present controversy would not have been continued nor so heated. The very impatience with which Meyer and Leopold deny all that Talbot claims, while it seems so plausible to us, can hardly be explained on any other basis than that they do not see these hard curds as we do.

Hard curds, are, furthermore, evidently a digestive disturbing factor, and the arguments of Meyer and Leopold, based on metabolism, to show the harmlessness of casein, are wholly beside the question. It is easy to agree with these observers that boiled casein produces no digestive or metabolic disturbance that is recognizable at present, but raw casein in milk can produce a digestive disturbance, in that hard curds may occur when it is fed.

The question of protein digestion, so recently settled for many of us by Heubner, Czerny and Finkelstein, and their schools, if the above conclusions are warranted by the evidence, must be opened again. As shown above, when hard curds appear in the stools, depending wholly on the baby or on the amount of casein given in raw milk, other evidences of indigestion commonly appear. If the same food is boiled, commonly all of the symptoms of indigestion disappear as well as the curds. Whether the curds are an evidence of a primary protein indigestion, secondarily causing mechanical or other irritation; or whether they are an accompaniment of some other digestive disturbance caused by feeding raw milk. just as mucus, curds, increased peristalsis, etc., accompany, say, a dose of castor oil, remains to be determined. It seems to me that these hard curds must be given the same weight as an evidence of casein indigestion that is given to the small soft curds, as an evidence of fat indigestion, although the two processes are wholly different.

Practically, that is, clinically, one's conclusions concerning protein digestion in feeding cow's-milk are but little influenced by the evidence that I have presented, that under certain limited conditions cascin may appear undigested in the infant's stool as hard curds. In the experiments that I have given the hard curds were in reality an artefact. Even in the use of diluted, raw, whole milk mixtures as commonly used, these curds rarely appear unless the baby is given a larger amount of milk than it should have; i. e., when a baby is improperly fed. Indeed, even when hard curds appear, under these conditions, it is probable in many cases that the fat or the carbohydrate has produced an indigestion, and the hard curds are simply a result of an increased peristalsis that has 
swept them through before they could be digested completely. The appearance of these hard curds, when proper amounts of raw milk are used, will be limited very largely to those patients who are getting fatfree milk, and to a very small percentage of patients in whom, for some reason, there is a peculiar temporary susceptibility to casein indigestion. There is some evidence in my experience that raw milk will at times produce colic, or discomfort that is relieved by boiling the milk. Even in an adult $I$ have known 24 ounces of raw milk repeatedly to produce colicky pains and even a slight diarrhea, while the same amount of boiled milk under identical conditions never causes discomfort. Even when raw milk is used in therapeutic amounts, we must conclude, in spite of these isolated cases, that the dictum that casein produces neither digestive nor metabolic disturbance is very nearly true. Certainly it would be wholly unjustifiable to speak of it as belonging, as a disturbing factor in infant feeding, even remotely in the same class as the fat or the sugar.

In this paper I am offering no therapeutic suggestion of any kind with reference to whether milk should commonly be boiled or not. I cannot refrain from saying a word, however, concerning certain therapeutic measures. Certain very diverse foods, commonly recognized as easily digested foods, such as buttermilk, condensed milk, dried milks, sodium citrated or otherwise alkalinized milks, all have one thing in common-they do not curdle in hard masses as raw milk does.

On the other hand, it is certainly a question whether the use of rennin, as in pegnin, or chymogen, has decided, or, indeed, any advantages when the milk is previously boiled, over boiled milk itself; and when not boiled the result is not satisfactory because of the toughness of the small curds that are formed.

Even in the preparation of Eiweissmilch, with raw and boiled milk, respectively, there is an appreciable difference in the consistency and amount of the curd and the amount of whey extracted; hence a difference in the ultimate food itself in the very respect that makes it unique and effective as a therapeutic measure. He who uses raw Eiweissmilch will get very different results from another who uses boiled milk in its preparation. The fact that Finkelstein, Langstein and Meyer make no reference to whether boiled or raw milk should be used in preparing this food, shows how little German pediatricians appreciate this great difference between raw and boiled milk, or rather how unfamiliar, practically, they are with the use of raw milk as an infant food and with the one evident digestive disturbance that it occasionally causes, i. e., the formation of hard curds.

4632 Lake Avenue.

\section{REFEREXCES}

Talbot, F. B.: Composition of Large Curds in Infants' Stools, Boston Med. and Surg. Jour., June 11, 1908, p. 905; The Composition of Small Curds of 
Infants' Stools, Boston Med. and Surg. Jour., Jan. 7, 1909, p. 13; Casein Curds of Infants' Stools, Arch. Pediat., December, 1910, p. 919; Casein Curds in Infants' Stnols, Biologic Proof of their Casein Origin, Arch. Pediat., June, 1910, p. 440. Meyer, L. F., and Leopold, J. S.: On the So-called Casein Masses in Infants' Stools, Arch. Pediat., October, 1909, p. 773, and February, 1910, p. 126.

Southworth, T. S., and Schloss, O. M.: The Hard Curds of Infants' Stools; their Origin, Nature and Transformation, Arch. Pediat., April, 1909, p. 241.

Czerny, A.: Des Kindes Ernährung, Ernährungs-Störungen, und ErnährungsTherapie, 1909; Franz Denticke, Leipsic and Vienna.

Langstein and Meyer: Säuglingsernährung und Säuglingsstoffwechsel, 1910; J. F. Bergman, Wiesbaden.

Finkelstein, H., and Meyer, L. F.: Ueber Eiweissmilch, Jahrb. f. Kinderh., May and June, 1910. 